\title{
Comparisons of Pathological Responses in Carrot to Root-knot Nematodes
}

\author{
Yunhee Seo ${ }^{1}$, Yong Su Kim², Yong Park ${ }^{2}$ and Young Ho Kim ${ }^{1 *}$ \\ ${ }^{I}$ Deaprtment of Agricultural Biotechnology and Research Institute of Agriculture and Life Sciences, Seoul National Univer- \\ sity, Seoul 151-921, Korea \\ ${ }^{2}$ KC Carrot Breeding Institute Co., Ltd., Daegu 706-850, Korea
}

(Received on June 15, 2015; Revised on July 31, 2015; Accepted on August 4, 2015)

Carrot (Dacus carota var. sativus) is one of the top-ten most economically important vegetable crops produced worldwide, and the root-knot nematodes, Meloidogyne spp., are one of the most important pests in the carrot. In Korea, M. hapla and M. incognita are presumed to be the major root-knot nematodes distributing mostly in open carrot fields and greenhouses, respectively. In our study, currently-developed and commercial carrot cultivars and the parental lines were examined for their pathological responses to $M$. incognita and M. hapla 7 weeks after inoculation with about 1,000 secondstage juveniles (J2) of the nematodes. All the carrot cultivars and lines showed susceptible responses to both nematodes with the gall index (GI) of 2.4-4.4, which were always higher on the carrot plants infected with M. incognita than M. hapla. Gall sizes were remarkably larger with more serious reduction of the root growths in the plants infected with $M$. incognita than M. hapla, suggesting the carrot lines examined in our study were more susceptible to the former than the latter. In the infection sites of the root tissues, giant cells were more extensively formed, occupying larger stellar regions with the prominent destruction of adjacent $\mathrm{xylem}$ vessels by $M$. incognita than $M$. hapla. All of these results suggest $M$. incognita affect more seriously on the carrot plants that are grown in greenhouses, compared to $M$. hapla that has a major distribution in open carrot fields, which would be used for determining cropping systems based on target nematode species, their damage and pathological characteristics.

\footnotetext{
*Corresponding author.

Phone) +82-2-880-4675, FAX) +82-2-873-2317

E-mail)yhokim@snu.ac.kr

This is an open access article distributed under the terms of the Creative Commons Attribution License (http://creativecommons.org/licenses/by/2.0), which permits unrestricted use, distribution, and reproduction in any medium, provided the original work is properly cited.
}

Keywords : carrot, gall formation, giant cell, Meloidogyne spp., pathological responses

Carrot (Dacus carota var. sativus) is one of the top-ten economically important crops, second only to the potato worldwide. It is also an important root vegetable in Korea; its total cultivation area of 2,849 ha composed of mostly fields $(83.1 \%)$ and some greenhouses $(16.9 \%)$ with the total annual production amount of 93,694 tons in 2011 (Ministry for Food, Agriculture, Forestry and Fisheries, Republic of Korea, 2012).

Carrot cultivation aims to produce taproot, of which the quantitative and qualitative production losses are brought about by the infection of soil-borne plant pathogens such as bacteria, fungi and nematodes (Korean Society of Plant Pathology, 2009). Among them, root-knot nematodes are serious pathogens in the carrot worldwide (Bridge and Starr, 2007; Johnson and Fassuliotis, 1984; Roberts, 1987; Siroka and Fernandez, 1990).

Four root-knot nematode species including M. hapla, $M$. incognita, M. arenaria, and $M$. javanica were reported in the carrot worldwide and in Korea (Bridge and Starr, 2007; Korean Society of Plant Pathology, 2009). Among them M. hapla is the most common species infesting open fields of temperate climatic regions, while the others are tropical root-knot nematode species found in hot tropical or warm climates (Anwar and McKenry, 2010; Bridge and Starr, 2007). The most prevalent root-knot nematode species in Korea is presumed to be M. hapla, considering that the major carrot-growing areas are open fields (winter-season cultivation) in Jeju and high-land areas (summer-season cultivation) in Gwangwon provinces (Ministry for Food, Agriculture, Forestry and Fisheries, Republic of Korea, 2012). However, the other three root-knot nematodes may be able to spread throughout carrot fields in the near future with increasing temperatures due to global climate change (Chakraborty et al., 2000; Harris et al., 2006; IPCC, 2007) 
and/or during greenhouse cultivation, in which $M$. incognita and M. arenaria are most common (Kim, 2001; Kim et al., 2001b). In a temperate-climactic region, M. incognita population is popular as a warm-temperature nematode (Sardanelli et al., 1983).

Several chemical and cultural practices may be applied for the control of the root-knot nematodes, including nematicide treatment, soil admixture, rotation and flooding (Kim et al., 2001a; Kim and Choi, 2001). Among them, the use of resistant cultivars for rotation is an ideal method of controlling the nematodes on carrot with no or little additional cost required for the nematode control (Kinlock and Hinson, 1972; Rhoades, 1976). However, there is currently no cultivar available in Korea with high level of resistance to $M$. incognita and M. hapla, but only two studies were conducted in relation to the screening of Korean carrot lines against the infections of $M$. incognita (Seo et al., 2014) and M. hapla (Park et al., 2014).

The effective cultural practices for controlling root-knot nematodes rely on cropping systems (Raymundo, 1985). It is important to verify preliminary things such as target nematode species, their damage and biological characteristics and host-parasite relations for determining cropping systems in the use of nematode-resistant crop to increase the control efficacy and reduce the control cost. Therefore, this study aimed to examine pathological responses of carrot lines developed in Korea to the infection of the two important root-knot nematodes, $M$. incognita and $M$. hapla, which may be helpful in the identification of root-knot nematode species and in determining economic cropping systems based on the nematode damage severity and plant responses to the nematode infection.

A commercial carrot cultivar Shinheukjeon-5-chon (SHC) and a currently-developed hybrid line MJ 11-8 $\left(\mathrm{F}_{1}\right)$ and the crossing parental lines MJ 11-8 (q) and MJ 11-8 $\left.\left(\widehat{J}^{\Uparrow}\right)\right\}$ developed in KC Carrot Breeding Institute, Korea, were used for the nematode inoculation. The root-knot nematodes $M$. incognita Race 1 and $M$. hapla were used as inocula as used in the other previous studies (Park et al., 2014; Seo et al., 2014). Seeds of the carrot lines were germinated in vermiculite at $20^{\circ} \mathrm{C}$ for 1 week and then planted in $9 \mathrm{~cm}$ (diameter) $\times 8 \mathrm{~cm}$ (depth) plastic pots filled with 1:1 mixture of river sand and potting soil mixture sterilized at $121^{\circ} \mathrm{C}$ for $15 \mathrm{~min}$. Egg masses of $M$. incognita and $M$. hapla hand-picked using forceps from the pure cultures maintained on chili pepper (Capsicum annuum cv. Bugang) and tomato (Lycopersicon esculentum cv. Rutgers), respectively, under greenhouse conditions were incubated on Baermann funnels for 3-5 days for eggs to hatch into second-stage juveniles (J2) of the nematodes
(Son et al., 2008; Southey, 1986). J2 of the nematodes collected from the funnels were diluted in sterile distilled water (SDW) and inoculated on the seven-week-old carrot seedlings at 4-6 true leaf stages by pouring $10 \mathrm{ml}$ nematode solutions containing about 1,000 J2 around the plant rhizosphere with five replications for each carrot line. The carrot seedling pots inoculated with the nematodes were arranged in a randomized complete block design in greenhouse benches and grown at $20 \pm 5^{\circ} \mathrm{C}$. Seven weeks after nematode inoculation, plants were carefully uprooted from pots, and the root systems were gently washed with tap water to remove adhering soil. The roots were examined visually for root gall formation on each root system and the root gall formation was graded using the gall index (GI) based on the percentages of roots galled as $0=0-10 \%, 1=$ $11-20 \%, 2=21-50 \%, 3=51-80 \%, 4=81-90 \%$, and $5=$ 91-100\% (Baker, 1985), which were expressed as averages \pm standard deviations of five replications. The degrees of pathological responses of carrot lines to the nematode infection were graded using the GI to be highly resistant (HR) when $\mathrm{GI} \leq 0.1$, resistant $(\mathrm{R})$ when $\mathrm{GI} \leq 1.0$, and susceptible (S) when GI > 1.0 (Sasser et al., 1984).

The carrot plants infected with the root-knot nematodes were used to examine their histopathological responses to the nematode infections. For this, infected carrot root segments (containing galls) were fixed with Karnovsky's fixative in $0.05 \mathrm{M}$ cacodylate buffer $(\mathrm{pH} 7.2$ ) for $4 \mathrm{~h}$. The root segments were washed in $0.05 \mathrm{M}$ cacodylate buffer ( $\mathrm{pH} 7.2)$ three times for $15 \mathrm{~min}$ each and post-fixed in $1 \%$ osmium tetroxide in the same buffer for $2 \mathrm{~h}$ at $4^{\circ} \mathrm{C}$ in a refrigerator. Then they were washed briefly with distilled water for $1-2$ min, and en block stained in $0.5 \%$ uranyl acetate overnight at $4^{\circ} \mathrm{C}$ in a refrigerator. The specimens were then dehydrated in an ethanol series of $30 \%, 50 \%, 80 \%$ and $90 \%$, and finally three times in $100 \%$ ethanol each for $10 \mathrm{~min}$. The specimens were further treated with two changes of $100 \%$ propylene oxide each for $15 \mathrm{~min}$ and embedded in Spurr's epoxy resin (Spurr, 1969), followed by polymerization at $70^{\circ} \mathrm{C}$ for $8 \mathrm{~h}$ for the embedding of the specimens. The embedded specimens were sectioned at $600 \mathrm{~nm}$ thicknesses with a glass knife on a MT-X ultramicrotome (RMC, Tucson, AZ, USA) and observed under a compound light microscope (Axiophot; Carl Zeiss, Oberkochen, Germany) after staining them with $1 \%$ toluidine blue $\mathrm{O}$ in $2 \%$ sodium tetra-borate.

Root-knot galls were readily formed on all carrot cultivar and lines tested, regardless of the nematode species, all of which were categorized susceptible as the GI was 2.4-4.4 (Table 1). The GI caused by the two nematodes was highest in MJ 11-8 (+) and lowest in MJ 11-8 ( $\overbrace{}^{\Uparrow})$, respectively. 
Table 1. Root-knot gall formation as indicated by gall index (GI) and pathological response (PR) on a commercial carrot cultivar Shinheukjeon-5-chon (SHC) and a presumed commercial hybrid line MJ 11-8 (F1) and the crossing parental lines \{MJ 11-8 () and MJ 11-8 (ふ) infected with Meloidogyne incognita and $M$. hapla examined 7 weeks after inoculation with 1000 secondstage juveniles (J2) per plant

\begin{tabular}{clllll}
\hline \multirow{2}{*}{$\begin{array}{c}\text { Cultivar } \\
\text { (line) }\end{array}$} & \multicolumn{2}{c}{ M. incognita } & & \multicolumn{2}{c}{ M. hapla } \\
\cline { 2 - 3 } \cline { 5 - 5 } & \multicolumn{1}{c}{$\mathrm{GI}^{\mathrm{a}}$} & $\mathrm{PR}^{\mathrm{b}}$ & & $\mathrm{GI}$ & $\mathrm{PR}$ \\
\hline SHC & $3.8 \pm 0.8 \mathrm{abx}{ }^{\mathrm{c}}$ & $\mathrm{S}$ & & $3.0 \pm 0.7 \mathrm{abx}$ & $\mathrm{S}$ \\
MJ 11-8 $\left({ }^{\text {đ }}\right)$ & $3.0 \pm 0.7 \mathrm{bx}$ & $\mathrm{S}$ & & $2.4 \pm 0.5 \mathrm{bx}$ & $\mathrm{S}$ \\
MJ 11-8 $(+)$ & $4.4 \pm 0.9 \mathrm{ax}$ & $\mathrm{S}$ & & $3.6 \pm 1.1 \mathrm{ax}$ & $\mathrm{S}$ \\
MJ 11-8 $\left(\mathrm{F}_{1}\right)$ & $3.6 \pm 0.9 \mathrm{abx}$ & $\mathrm{S}$ & & $2.4 \pm 0.5 \mathrm{by}$ & $\mathrm{S}$ \\
\hline
\end{tabular}

*Figures are averages and standard deviations of five replications ${ }^{\mathrm{a}} \mathrm{Gall}$ index (GI) scored by the percentages of roots galled as $0=$ $0-10 \%, 1=11-20 \%, 2=21-50 \%, 3=51-80 \%, 4=81-90 \%$, and $5=91-100 \%$ (Baker, 1985)

${ }^{b}$ Pathological response (PR) based on GI: highly resistance (HR) when $\mathrm{GI} \leq 1.0$; resistant (R) when $\mathrm{GI} \leq 1.0$; and susceptible (S) when GI > 1.0 (Sasser et al., 1984).

${ }^{\mathrm{c}}$ The same first $(\mathrm{a}, \mathrm{b}, \mathrm{c})$ and last $(\mathrm{x}, \mathrm{y})$ letters denote no significant differences at $P \leq 0.05$ in a column and row, respectively, by least significant difference (LSD) test.

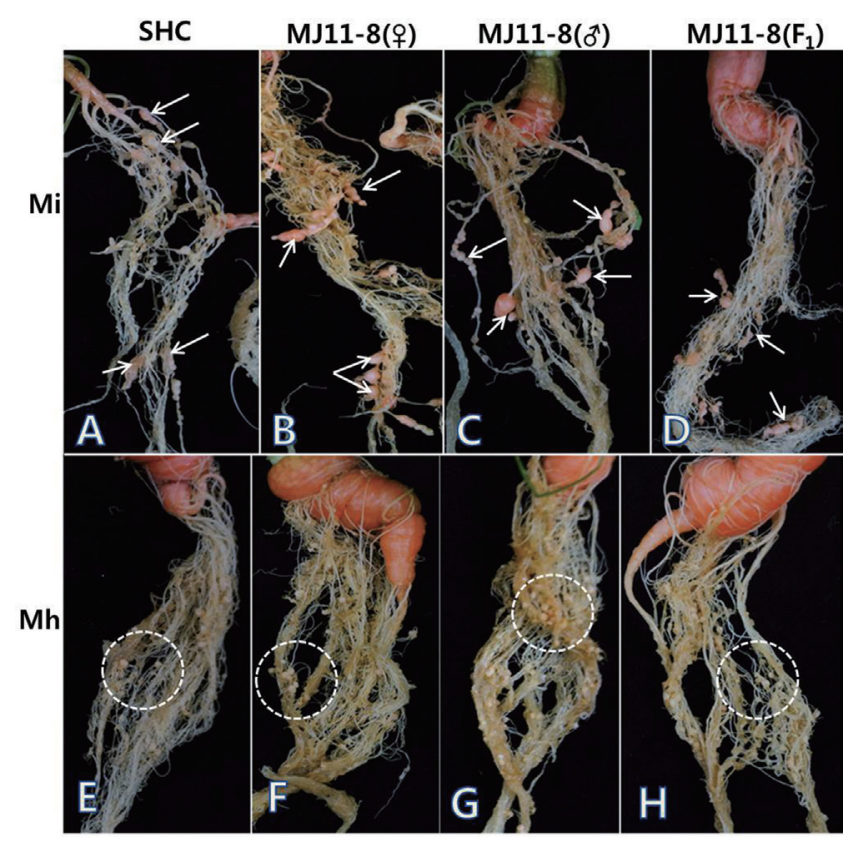

Fig. 1. Gall formation on a commercial carrot cultivar Shinheukjeon5-chon (A, E), the crossing parental lines $\{\mathrm{MJ} 11-8$ (ㅇ) (B, F) and MJ 11-8 (ठ) $(\mathrm{C}, \mathrm{G})\}$ and their hybrid line MJ 11-8 (F1) $(\mathrm{D}, \mathrm{H})$ infected with Meloidogyne incognita (A-D) and M. hapla $(\mathrm{E}-\mathrm{H})$ examined 7 weeks after inoculation. Note the differences of root-knot gall size $\{$ arrows $(\mathrm{A}-\mathrm{D})$ and circles $(\mathrm{E}-\mathrm{H})$ \} and tap and lateral root growths between M. incognita and M. hapla.
In the same carrot lines, GI of $M$. incognita was always higher than that of $M$. hapla with or without significant differences at $P \leq 0.05$. Also, the root-knot gall sizes were remarkably larger in all carrot lines infected with $M$. incognita than M. hapla, which was accompanied by the poorer growth of the tap root and lateral root system in the former than the latter (Fig. 1).

The severity of root-knot gall formation differs generally depending on nematode population density showing the increased number and size of the root-knot galls due to the large numbers of nematodes penetrating the root overall and in close proximity, resulting in the formation of more numerous and larger galls (Mitkowski and Abawi, 2003). However, the difference in the severity of galling in our study may not be due to the nematode population sizes in the soil because about the same amount of $\mathrm{J} 2$ was used as inoculum for both nematodes. It was known that M. hapla produces tiny galls, while $M$. incognita produces larger galls and more severe stunting, yellowing and wilting symptoms on a wide variety of vegetable crops including the carrot (Sardanelli et al., 1983). It is also noticed in our previous studies that remarkably larger galls are formed in susceptible carrot lines infected with $M$. incognita (Seo et al., 2014) than those infected with M. hapla (Park et al., 2014). It has been experienced that the root-knot galls formed on carrots grown in Jeju province (open fields) were characteristically small as those formed by M. hapla in the present study (unpublished data, 2014). This suggests that not only the carrot lines used in our study but also other Korean carrot lines and cultivars susceptible to the nematodes may be more susceptible to $M$. incognita, forming lager galls than M. hapla.

Light micrographs of infection sites in susceptible carrot lines infected with $M$. incognita (Fig. 2A-C) and M. hapla (Fig. 2D-F) at 7 weeks after inoculation showed the formation of well-developed giant cells with extensive xylem vessels formed adjacent to them. These structural characteristics of the giant cells in carrot root tissues may be related to the typical susceptible responses to the nematode infection as is noticed in tomato cultivars and lines susceptible to the root-knot nematode (Moon et al., 2010). Giant cells may provide the parasites with the energy required to invade plant roots (Shepherd and Huck, 1989). In host plants infected with Meloidogyne spp., the formation of giant cells incites the photosynthates mobilized from shoots to roots, especially to the giant cells, where the nutritional materials are removed and taken up by the infecting nematode that functions as a metabolic sink (Hussey, 1985).

In our study, the giant cells induced by $M$. incognita 


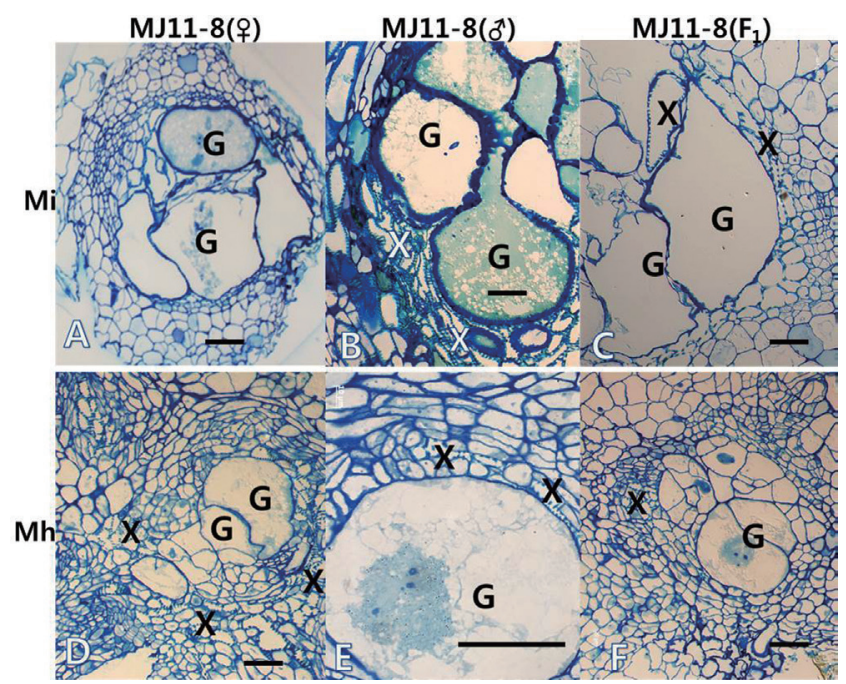

Fig. 2. Light micrographs of infection sites in the crossing parental lines $\{$ MJ 11-8 (ㅇ) (A, D) and MJ 11-8 (ठ) (B, E)\} and their hybrid progeny line MJ 11-8 $\left(\mathrm{F}_{1}\right)(\mathrm{C}, \mathrm{F})$ infected with Meloidogyne incognita $(\mathrm{A}-\mathrm{C})$ and $M$. hapla $(\mathrm{D}-\mathrm{F})$ examined 7 weeks after inoculation, showing the formation of giant cells $(\mathrm{G})$ and xylem vessels $(\mathrm{X})$ adjacent to the giant cells. Note the giant cells induced by $M$. incognita $(\mathrm{A}-\mathrm{C})$ occupy larger central areas of the root system accompanying the more extensive destruction of xylem vessels than those induced by M. hapla (D-F). Bars $=50 \mu \mathrm{m}$.

occupied larger central areas (stellar regions) of the root system accompanied by the more extensive destruction of xylem vessels than those induced by M. hapla (Fig. 2). These morphological features indicate that $M$. incognita may block the stele more extensively than $M$. hapla, influencing adversely on the nutrient translocation through xylem vessels in the stele (Hunter, 1958). This may cause nutritional deficiencies more by $M$. incognita, leading to the root growth more suppressed as was noticed in Fig. 1 than by M. hapla.

One of the most widespread pests worldwide is the rootknot nematodes that are the most common and destructive among the plant-parasitic nematodes whose damage to crop plants worldwide has been estimated about 100 billion dollars (Chitwood, 2003; Oka et al., 2000; Sasser and Carter, 1985). The damage caused by root-knot nematodes, especially by $M$. incognita, is catastrophic to vegetables in tropics and semi-tropics (Mai, 1985). In carrots, the rootknot nematode is economically the second most serious disease pest of carrot worldwide next to Alternaria leaf blight (Davis, 2004), which may be hold true to the carrot production in Korea. For the root-knot nematode control, the use of resistant crop cultivars is a highly effective and economically reliable method with no or little additional cost for the nematode control (Kinlock and Hinson, 1972;
Rhoades, 1976). In Korea, there is an undergoing study on the breeding of Korean carrot lines resistant to the rootknot nematode (Seo et al., 2014). Therefore, this study may provide information on the importance of root-knot nematodes in carrot cultivation and preliminary aspects that should be used for determining cropping systems based on target nematode species, their damage and pathological characteristics, increasing nematode control efficacies.

\section{Acknowledgments}

This study was conducted with a financial support from the Ministry for Food, Agriculture, Forestry and Fisheries, Republic of Korea.

\section{References}

Anwar, S. A. and McKenry, M. V. 2010. Incidence and reproduction of Meloidogyne incognita on vegetable crop genotypes. Pakistan J. Zool. 42:135-141.

Baker, K. R. 1985. Nematode extractions and bioassays. In: An advanced treatise on Meloidogyne. Vol. II. Methodology, eds. by K.R. Baker, C.C. Carter, and J.N. Sasser, pp. 19-35. North Carolina State University, NC, USA.

Bridge, J. and Starr, J. L. 2007. Plant nematodes of agricultural importance: A color handbook. Academic Press, San Diego, CA, USA.

Chakraborty, S., Tiedemann, A. V. and Teng, P. S. 2000. Climate change: Potential impact on plant disease. Environ. Pollut. 108:317-326.

Chitwood, D. J. 2003. Research on plant-parasitic nematode biology conducted by the United States Department of Agriculture - Agricultural Research Services. Pest Manag. Sci. 59:748-753.

Davis, R. M. 2004. Carrot diseases and their management. In: Diseases of Fruits and Vegetables Vol. 1, ed. by S.A.M.H. Naqvi, pp. 297-440. Kluwer Academic Publishers, Dordrecht, Netherlands.

Harris, J. A., Hobbs, R. J., Higgs, E. and Aronson, J. 2006. Ecological restoration and global climate change. Restor. Ecol. 14:170-176.

IPCC (Intergovernmental Panel on Climate Change). 2007. Climate change. In: Synthesis report. Contribution of working group I, II, and III to the fourth assessment of the Intergovernmental Panel on Climate Change, eds. by R.K. Pachauri and A. Reisinger. IPCC, Geneva, Switzerland.

Hunter, A. H. 1958. Nutrient absorption and translocation of phosphorus as influenced by the root knot nematode (Meloidogyne incognita acrita). Soil Sci. 86:245-250.

Hussey, R. S. 1985. Host-parasite relationships and associated physiological changes. In: An advanced treatise on Meloidogyne. Vol. I. Biology and control, eds. by J.N. Sasser and C.C. Carter, pp. 143-154. North Carolina State University, NC, 
USA.

Johnson, A. W. and Fassuliotis, G. 1984. Nematode parasites of vegetable crops. In: Plant and insect nematodes, ed. by W.R. Nickle, pp. 323-327. Marcel Dekker, Inc., New York, N. Y., USA.

Kim, D. G. 2001. Occurrence of root-knot nematodes on fruit vegetables under greenhouse conditions in Korea. Res. Plant Dis. 7:69-79 (in Korean).

Kim, D. G. and Choi, S. K. 2001. Effects of incorporation method of nematicides on reproduction of Meloidogyne arenaria. Kor. J. Appl. Entomol. 40:89-95 (in Korean).

Kim, D. G., Choi, D. R. and Lee, S. B. 2001a. Effects of control methods on yields of Oriental melon in fields infested with Meloidogyne arenaria. Res. Plant. Dis. 7:42-48 (in Korean).

Kim, D. G., Lee, Y. G. and Park, B. Y. 2001b. Root-knot nematode species distributing in greenhouses and their simple identification. Res. Plant Dis. 7:49-55 (in Korean).

Kinloch, R. A. and Hinson, K. 1972. The Florida program for evaluating soybean (Glycine max (L.) Merr.) genotypes for susceptibility to root-knot nematode disease. Proc. Soil Crop Sci. Florida 32:173-176.

Korean Society of Plant Pathology. 2009. List of plant diseases in Korea, 5th ed. Korean Society of Plant Pathology, Suwon, Korea.

Mai, W. F. 1985. Plant-parasitic nematodes: their threat to agriculture. In: An advanced treatise on Meloidogyne. Vol. I. Biology and control, eds. by J. N. Sasser and C.C. Carter, pp. 11-18. North Carolina State University, NC, USA.

Ministry for Food, Agriculture, Forestry and Fisheries, Republic of Korea. 2012. Food, agriculture, forestry and fisheries statistic yearbook 2012. Ministry for Food, Agriculture, Forestry and Fisheries, Republic of Korea.

Mitkowski, N. A. and G. S. Abawi. 2003. Root-knot nematodes. The Plant Health Instructor. DOI:10.1094/PHII-2003-0917-01

Moon, H. S., Khan, Z., Kim, S. G., Son, S. H. and Kim, Y. H. 2010. Biological and structural mechanisms of disease development and resistance in chili pepper infected with the rootknot nematode. Plant Pathol. J. 26:149-153.

Oka, Y., Koltai, H., Bar-Eyal, M., Mor, M., Sharon, E. and Spiegel, Y. 2000. New strategies for the control of plant-parasitic nematodes. Pest Manag. Sci. 56:983-988.

Park, J., Seo, Y. and Kim, Y. H. 2014. Biological control of Meloidogyne hapla using an antagonistic bacterium. Plant Pathol. J. 31:288-298.
Raymundo, S. A. 1985. Cropping systems research and root-knot nematode control. In: An advanced treatise on Meloidogyne. Vol. I. Biology and control, eds. by J.N. Sasser and C.C. Carter, pp. 277-282. North Carolina State University, NC, USA.

Rhoades, H. L. 1976. Effects of Indigofera hirsuta on Belonolaimus longicaudatus, Meloidogyne incognita, and M. javanica and subsequent crop yield. Plant Dis. Reptr. 60:384-386.

Roberts, P. A. 1987. The influence of planting date of carrot on Meloidogyne incognita reproduction and injury to roots. Nematologica 33:325-342.

Sardanelli, S., Krusberg, L. R. and Kantzes, J. G. 1983. Plant parasitic nematodes in Maryland. Fact Sheet 381. Univ. of MD Coop. Ext., Univ. of Maryland. College Park, MD, USA.

Sasser, J. N. and Carter, C. C. 1985. Overview of the International Meloidogyne Project 1975-1984. In: An advanced treatise on Meloidogyne. Vol. I. Biology and control, eds. by J.N. Sasser and C.C. Carter, pp. 9-24. North Carolina State University, NC, USA.

Sasser, J. N., Carter, C. C. and Hartman, K. M. 1984. Standardization of host suitability studies and reporting of resistance to root-knot nematodes. Crop Nematode Research Control Project, NCSU/USAID. Department of Plant Pathology, NCSU, Raleigh, NC, USA.

Seo, Y., Park, J., Kim, Y. S., Park, Y. and Kim, Y. H. 2014. Screening and histopathological characterization of Korean carrot lines for resistance to the root-knot nematode Meloidogyne incognita. Plant Pathol. J. 31:75-81.

Shepherd, R. L. and Huck, M. G. 1989. Progression of root-knot nematode symptoms and infection on resistant and susceptible cottons. J. Nematol. 21:235-241.

Siroka, R. A. and Fernandez, E. 1990. Nematode parasites of vegetables. In: Plant parasitic nematodes in subtropical and tropical agriculture, eds. by M.R. Luc, A. Siroka, and J. Bridge, pp. 319-392. CAB Bioscience, Egham, UK.

Son, S. H., Khan, Z., Kim, S. G. and Kim, Y. H. 2008. Effects of seed treatment with rhizobacterium, Paenibacillus species on management of root-knot nematode-Fusarium wilt fungus disease complex in tomato plants. Russ. J. Nematol. 16:97105.

Southey, J. F. 1986. Laboratory methods for work with plant and soil nematodes. Ministry of Agriculture Fisheries and Food, HMSO, London, UK.

Spurr, A. R. 1969. A low viscosity epoxy resin embedding medium for electron microscopy. J. Ultrastr. Res. 26:31-43. 